\title{
Management of L-Dopa Overdose in the Competitive Inhibition State [Retraction]
}

Hinz M, Stein A, Cole T. Drug Healthc Patient Saf. 2014;6:93-99.

The Editor-in-chief and Publisher of Drug, Healthcare and Patient Safety wish to retract the published article.

Following the conclusion of our investigation the decision has been made to retract the published article. The authors did not provide the requested IRB and informed consent information relating to this study and it was determined the study did not meet the ethical publication requirements for research involving human subjects. These requirements are based on guidelines issued by the World Medical Association and the International Committee of Medical Journal Editors. Additionally, the authors did not provide the study protocols, raw data and other study documents relating to this study as requested. Given our concerns about the standard of research ethics, competing interests and that the authors have not supplied the information we requested to verify and validate the reported findings, the editor has determined the article should be retracted.

Our decision-making was informed by our policy on publishing ethics and integrity and the COPE guidelines on retraction.

The retracted article will remain online to maintain the scholarly record, but it will be digitally watermarked on each page as "Retracted".
Drug, Healthcare and Patient Safety

\section{Publish your work in this journal}

Drug, Healthcare and Patient Safety is an international, peer-reviewed open-access journal exploring patient safety issues in the healthcare continuum from diagnostic and screening interventions through to treatment, drug therapy and surgery. The journal is characterized by the rapid reporting of reviews, original research, clinical, epidemiological and post-marketing surveillance studies, risk management, health literacy and educational programs across all areas of healthcare delivery. The manuscript management system is completely online and includes a very quick and fair peer-review system. Visit http://www.dovepress.com/testimonials.php to read real quotes from published authors. 